\title{
Pesquisa de Salmonella spp. em frangos de corte criados em galpões climatizados de uma integração na região Oeste do Paraná ${ }^{1}$
}

\section{Detection of Salmonella spp. in broilers raised in a sealed buildings of integration in western Paraná}

\author{
Leoni Kappes Ravagnani ${ }^{2}$; Renata Olivotto Agostinis ${ }^{2}$; Luciana Kazue Otutumi ${ }^{3}$; \\ Edna Tereza Lima ${ }^{4}$; Jovanir Inês Muller Fernandes ${ }^{4}$; Lisiane de Almeida Martins ${ }^{5 *}$
}

\section{Resumo}

\begin{abstract}
Nos últimos 20 anos, o setor de avicultura foi o que mais investiu em tecnologia, o que justifica sua evolução em termos de produção. Esses ganhos ocorreram, devido à melhora dos índices de conversão alimentar, melhoramento genético, maior automação dos aviários e melhor manejo. A Salmonella spp. é uma bactéria que habita o trato intestinal do homem e dos animais. Quando as aves de um plantel contaminam-se com Salmonella, o controle torna-se difícil e com resultados duvidosos. As aves são reservatórios desta bactéria e podem disseminar este patógeno para outras aves, para o meio ambiente e para sua progênie. A produção de frangos de corte necessita de um programa de biosseguridade, para qualificar os produtos que são ofertados à população. Os lotes de frangos devem ser monitorados constantemente para averiguações a respeito da sua qualidade microbiológica, da qualidade da água e da ração. O objetivo deste trabalho foi pesquisar a contaminação por Salmonella spp. em frangos de corte criados em dois galpões climatizados de uma integração localizada na região oeste do Paraná. Por coletas de swabs de cloaca, swab de arrasto e pesquisa de Salmonella em fragmentos de órgãos, realizados em frangos de corte com idade variando entre $21 \pm 5$ dias de vida, no período compreendido entre abril a outubro de 2011. Foram coletados 100 swabs cloacais por lote de cada aviário, onde cada swab foi utilizado para amostrar duas aves, totalizando 1000 aves amostradas. Foram utilizados também 02 swabs de arrasto em cada galpão por lote, totalizando 20 amostras e fragmentos de órgãos de 10 aves de cada aviário por lote, onde foram coletados fragmentos do fígado, coração e baço de um pools de 5 aves e coletados cecos e tonsilas cecais de um pool de 5 aves por lote de cada aviário, totalizando 60 aves. As coletas e metodologia para pesquisa de Salmonella foram realizadas segundo os parâmetros preconizados pelo Ministério da Agricultura, Pecuária e Abastecimento (MAPA). Das 1000 aves amostradas por meio de swab de cloaca, nenhuma apresentou positividade para Salmonella spp, resultado semelhante foi encontrado nas 20 amostras de swab de arrasto e pools de fragmentos de órgãos das 60 aves amostradas. De acordo com os resultados encontrados concluímos que os frangos de corte criados em galpões climatizados de uma integração na região no oeste do Paraná encontram-se em boas condições sanitárias.
\end{abstract}

Palavras-chave: Swab de cloaca, swab de arrasto, saúde pública, pool

\footnotetext{
${ }^{1}$ Projeto financiado pela Universidade Paranaense, Umuarama, PR.

2 Discente(s) do Curso de Mestrado em Ciência Animal, Universidade Paranaense, UNIPAR, Umuarama. PR. E-mail:leonikappes@, hotmail.com; re_agostinis@hotmail.com

3 Profado Curso de Medicina Veterinária e Mestrado em Ciência Animal, UNIPAR, Umuarama. PR. E-mail: otutumi@unipar.br

${ }^{4}$ Prof $^{\text {as }}$ do Curso de Medicina Veterinária, Universidade Federal do Paraná, UFPR, Campus Palotina, Palotina, PR. E-mail: etlima@ufpr.br; jimfernandes@ufpr.br

${ }^{5}$ Prof ${ }^{\text {a }}$ do Curso de Medicina Veterinária e Mestrado em Ciência Animal, UNIPAR, Umuarama. PR. E-mail: lisiane.almeida. martins@gmail.com

* Autor para correspondência
} 


\begin{abstract}
Over the past 20 years, the poultry sector was the one that most invested in technology, which explains its evolution in terms of production. These gains were due to improved feed conversion ratios, breeding, increased automation and better management of aviaries. Salmonella spp. is a bacterium that inhabits both human being and animal intestinal tract. When birds of a breed are contaminated with Salmonella, control becomes difficult and results are unreliable. Birds are reservoirs of this bacterium and the pathogen can be spread to other birds, the environment and their progeny. The production of broilers needs a biosecurity program for qualifying products that are offered to the population. Flocks of chickens must be constantly monitored for inquiries regarding their microbiological quality, water quality and feed. The purpose of this study was to investigate the contamination by Salmonella spp. in broilers reared in two air-conditioned sheds of a Western Parana integration. The collection of sewer swabs, swab drag and Salmonella studies in fragments of organs, performed in broilers with ages between 21 \pm 5 days of life, took place from April to October, 2011. There were collected one hundred sewer swabs per flock in each aviary, and each swab was used to sample two birds, totaling 1,000 birds sampled. We also used 02 drag swabs in each shed per flock, totaling 20 samples and fragments of organs of 10 birds in each aviary per flock, where samples were collected from the liver, heart and spleen of a pool of 05 birds. There were also collected cecum and cecal tonsils of a pool of 05 birds per flock of each aviary, totaling 60 birds. Sampling and methodology for the Salmonella study were carried out according to the parameters established by the Ministry of Agriculture and Food Supplies (MAPA). None of the 1,000 birds sampled by sewer swab was positive for Salmonella spp. Similar result was found in the 20 samples of drag swab and pools of organs fragments from the 60 birds sampled. According to these results, we conclude that broilers reared in air-conditioned sheds of a Western Parana integration are in sanitary conditions.
\end{abstract}

Key words: Cloacal swabs, drag swabs, public health, pool

\section{Introdução}

O Brasil é considerado atualmente o maior exportador de carne de frango do mundo e ocupa a sétima posição do ranking mundial de produção de ovos. A carne de frango é o terceiro maior produto nas exportações do agronegócio, e o quinto na pauta brasileira de exportação (UBA, 2007). A Salmonella pertence à família Enterobacteriaceae. São conhecidas duas espécies deste gênero, a Salmonella bongori e Salmonella enterica. A S.enterica é dividida em seis subespécies, são elas, S. enterica, S. salamae, $S$. arizonae, $S$. diarizonae, $S$. houtenae e $S$. indica. Conhece-se mais de 2700 sorotipos bioquimicamente relacionados, mas apenas, 80 a 90 são os mais comuns em casos de infecções nas aves e nos humanos (BACK; BELTRÃO; LEÃO, 2006). Estima-se que 200 tipos de Salmonella estão associadas às toxinfecções alimentares, mas apenas 10 a 15 são mais frequentes e com maior importância (SCHARR, 2003). São bastonetes gram-negativos, não formam esporos, são aeróbios ou anaeróbios facultativos. Para diferenciação das espécies e as subespécies são feitas provas bioquímicas e verificação da combinação de fatores antigênicos somáticos $(\mathrm{O})$, flagelares $(\mathrm{H})$ e capsulares (Vi) (LE MINOR, 1988).

Por estar amplamente distribuída na natureza, a Salmonella pode infectar as aves, o homem, insetos, peixes, répteis e mamíferos em geral, causando a enfermidade denominada salmonelose. Nas aves pode causar infecção clínica ou subclínica, podendo assim permanecer como reservatório e fonte de infecção para humanos. Por ser um microorganismo de fácil adaptação, torna-se muito difícil a erradicação dos ambientes criatórios (BACK; BELTRÃO; LEÃO, 2006).

As Salmonellas podem causar três tipos de infecções nas aves, a Pulorose, (causada pelo sorotipo Salmonella Pullorum), tifo aviário (causada pela Salmonella Gallinarium), e o paratifo aviário (causado principalmente pela Salmonella Enteritidis e Salmonella Typhimurium) (BERCHIERI JUNIOR, 2000). 
As salmonelas paratíficas são consideradas um problema grave para a saúde pública, por ser um importante patógeno veiculado por alimentos (GOTTARDI; SOUZA; SCHMIDT, 2006; NADVORNY; FIGUEIREDO; SCHIMIDT, 2004).

Mesmo tentando controlar a salmonelose, ao sacrificar as aves infectadas, essa enfermidade é responsável por grandes perdas econômicas tanto para a avicultura, causando severos quadros de enterites e baixa produção, como também riscos a saúde pública (COX; BERRANG; CASON, 2000; NASCIMENTO; SANTOS, 2005).

Segundo Téo (2002), os ovos e os alimentos preparados com ovos crus ou cozidos e carnes de frango contaminados com Salmonella, manipulados sem higiene durante a preparação dos alimentos é um fator importante de contaminação cruzada, podendo causar toxinfecção alimentar em humanos.

O intestino dos animais e do homem são os principais reservatórios das salmonelas, (PEREIRA; SILVA, 2005). Elas têm como reservatórios os animais portadores assintomáticos, animais domésticos (como as aves e os suínos) e selvagens (BERCHIERT JUNIOR, 2000).

Nos humanos, a diarréia é o principal sintoma de salmonelose e sua intensidade varia de acordo com o paciente. Podem ocorrer outros sintomas, dentre eles, dores abdominais, cólicas, febre, náuseas, vômito e dor de cabeça (PELZER, 1989).

A Salmonella em humanos pode ser classificada em Salmonella typhi (febre tifóide), Salmonella paratyphi A, B e C (febre entérica) e demais Salmonellas sendo enquadradas como enfermidades entéricas. (FRANCO; LANDGRAF, 2005; SHINOHARA et al., 2008).

Segundo Tessari et al. (2003), para controlar a Salmonella spp. na avicultura são necessárias medidas de higiene na indústria e também no campo, onde busca-se reduzir o nível da bactéria no conteúdo intestinal das aves.

A monitoria permanente das aves deve ser feita através de sorologia (SAR) com antígeno licenciado pelo Ministério da Agricultura Pecuária e Abastecimento (MAPA). Poderão ser utilizados os testes de ensaio imunoenzimático (ELISA), soro aglutinação lenta em tubos (SAL) e microaglutinação. Para o diagnóstico bacteriológico e identificação do agente, poderão ser utilizados os testes de isolamento bacteriano e identificação de cultura.

A granja com programas de prevenção contra salmonelose, e a indústria, com as boas práticas de fabricação, podem diminuir a transmissão por alimentos de origem avícola (NADVORNY; FIGUEIREDO; SCHIMIDT, 2004).

Considerando que a Salmonella spp. podem acometer aves, gerando grandes prejuízos sócioeconômicos e podem ser de risco para a saúde pública, este trabalho tem como objetivo pesquisar a contaminação por Salmonella spp. em frangos de corte criados em galpões climatizados de uma integração na região noroeste do Paraná.

\section{Material e Métodos}

As aves utilizadas nesta pesquisa foram oriundas de uma propriedade localizada na região oeste do Paraná (Figura 1), constituída por dois galpões, com dimensões de 120 X 12 metros, cada. Num dos galpões as aves eram criadas no sistema convencional (cortinas amarelas) ventilação com uso depressão negativa, com exaustores que forçam a saída do ar, e o outro com no sistema Dark House, cujo aviário permanece todo vedado e fechado, com programa de luz de 12 horas alternado, e com sistema de resfriamento no lado de trás do galpão. 
Figura 1. Mapa destacando a região oeste do Paraná - local da realização dos aviários onde foi feita a pesquisa.

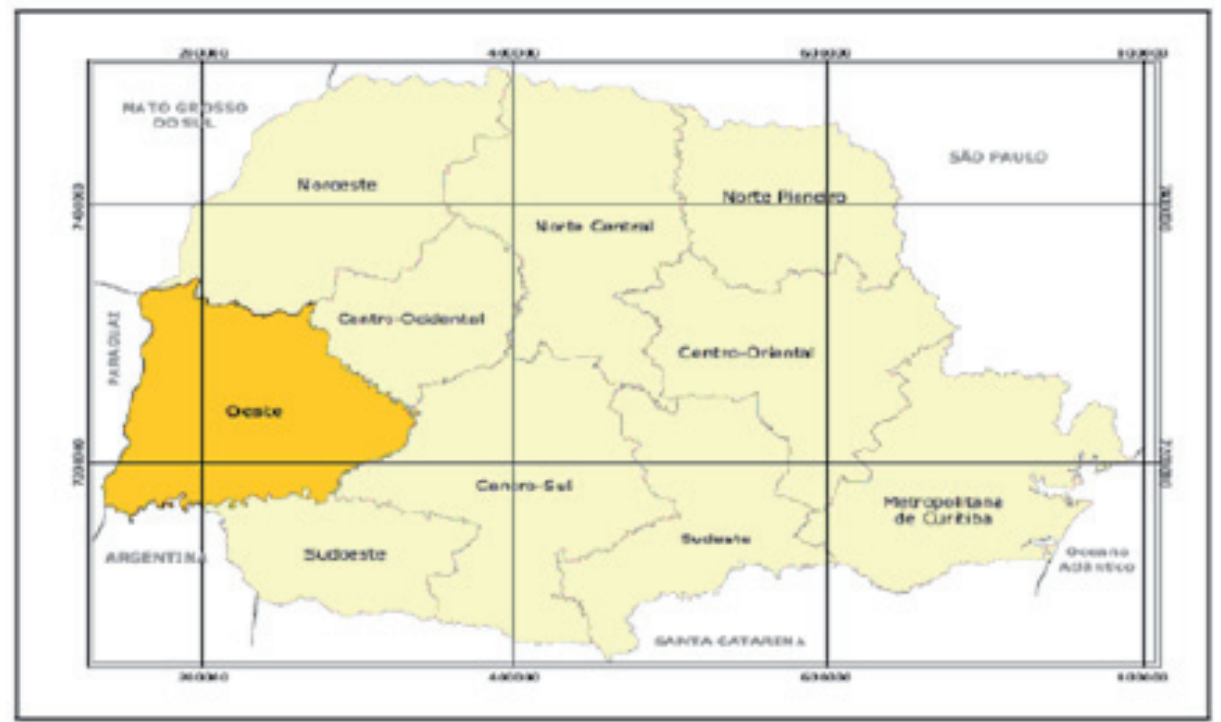

Fonte: Leituras regionais: IPARDES, 2012.

Determinação do plano amostral para swab de cloaca

Considerando a capacidade da granja e o erro amostral foi determinado o $n$ do experimento, segundo a fórmula descrita abaixo.

$$
\begin{gathered}
\mathbf{n}_{0}=1 / \mathbf{E}_{0}{ }^{2} \\
n=N \cdot n *{ }_{0} /\left(\mathrm{N}+\mathbf{n}{ }_{0}\right)
\end{gathered}
$$

Onde: $\mathrm{n}_{0}{ }_{0}=\mathrm{n}_{0}$

$\mathrm{n}=$ tamanho da população $=23.500$

$\mathrm{Eo}=$ erro amostral tolerável $=10 \%$

$\mathrm{n}_{\mathrm{o}}=$ primeira aproximação da amostra $=100$

$\mathrm{n}=$ aves amostradas $=99$

Considerando estes parâmetros de amostragem, aves amostradas ( $n$ ) seria de 99 aves. A amostragem de 100 aves evitaria perdas de erros amostrais sempre possíveis durante o trabalho (BARBETTA, 1999).

\section{Procedimento microbiológico}

Swab de cloaca e swab de arrasto

As colheitas das amostras de swab de arrasto e cloaca foram feitas de acordo com a Portaria $\mathrm{n}^{\mathrm{o}} 126$, de 03 de novembro de 1995 modificada. As quantidades de swabs de arrasto e os pools de fragmentos de órgãos foram colhidos segundo recomendações do Plano Nacional de Sanidade Avícola (PNSA) - portaria $n^{\circ} 193$, do Ministério da Agricultura, da Pecuária e do Abastecimento (MAPA, 1994), no período compreendido entre abril a outubro de 2011. As colheitas foram realizadas com idade variando entre $21 \pm 5$ dias. Foram colhidas 50 amostras de $s w a b$ cloacal, e dois de $s w a b$ de arrasto por lote de dois aviários, onde cada swab de cloaca foi utilizado para amostrar duas aves, totalizando 1000 aves amostradas. Cada swab de cloaca e de arrasto foi coletado e acondicionado em frasco com solução salina peptonada $1 \%$ tamponada. A seguir estes foram identificados e acondicionados sob refrigeração $\left( \pm 4^{\circ} \mathrm{C}\right)$ e enviados ao Laboratório de Doenças Infecciosas da Universidade Federal do Paraná - UFPR Campus Palotina. 
Os procedimentos das análises e as avaliações foram realizados utilizando-se os parâmetros preconizados pelo Ministério da Agricultura, Pecuária e Abastecimento (MAPA) Instrução Normativa $n^{\circ}$ 62, de Agosto de 2003 e Portaria $n^{\circ}$ 126, de 03 de novembro de 1995 modificadas.

Para o pré-enriquecimento, os swabs foram acondicionados em solução salina peptonada $1 \%$ tamponada, foram homogeneizados e incubados, a $36 \pm 1^{\circ} \mathrm{C}$ por 18 a 24 horas e a seguir, foram homogeneizados e submetidos ao enriquecimento seletivo em caldo Tetrationato e caldo RappaportVassiliadis, e incubados a $36^{\circ} \mathrm{C} \pm 1^{\circ} \mathrm{C}$ por um período de 18 a $24 \mathrm{~h}$. Após o período de incubação, as amostras foram semeadas em placas de petri contendo agar xilose-lisina desoxicolato (XLD) e em agar verde brillhante vermelho de fenol lactose sacarose (BPLS), as quais foram incubadas por 18 a 24 horas, $36^{\circ} \pm 1 \mathrm{C}$. Após a observação do crescimento bacteriano, foram selecionadas de 3 a 10 colônias que apresentavam morfologia típica de Salmonella spp., as quais foram submetidas as provas bioquímicas preliminares em caldo de uréia, Agar tríplice açúcar ferro (TSI), Agar lisina ferro (LIA) e agar sulfato indol motilidade (SIM), com incubação a $36 \pm 1^{\circ} \mathrm{C}$ por 18 a 24 horas.

Quando os isolados mostraram-se suspeitos de Salmonella, foram realizadas provas bioquímicas complementares, como a prova da desaminação da fenilalanina, reação de voges-proskauer, citrato de simmons, descarboxilação da ornitina, desidrolação da arginina, caldo malonato, prova fermentação da D-Glicose, prova fermentação da lactose, prova fermentação da sacarose, prova fermentação D-
Manitol, prova fermentação do dulcitol, prova fermentação da maltose, prova de soroaglutinação feita com anti-soro polivalente "O" .

\section{Necropsia e colheita dos órgãos}

Paralelamente foram realizadas necropsias e colheitas dos órgãos, sendo inicialmente realizada a eutanásia por deslocamento cervical de 20 aves (dez de cada aviário) com idade variando entre 21 dias \pm 5 respeitando os aspectos éticos preconizados pelo Conselho Federal de Medicina Veterinária Resolução $n^{\circ} 876$ de fevereiro de 2008. Foram colhidos assepticamente fragmentos de coração, fígado, baço, ceco e tonsilas cecais de dois pool de cinco aves por lote de dois aviários. Os fragmentos dos órgãos foram imersos em caldo cérebro coração (BHI). A pesquisa de Salmonella foi a mesma utilizada nos swabs.

Este experimento foi submetido ao Comitê de Ética em Pesquisa Envolvendo Experimentação Animal sob protocolo número 20013/2011.

\section{Resultados}

Não se isolou Salmonella spp. nas amostras colhidas em swabs de cloaca e amostras de swabs de arrasto, realizadas por lote em cada galpão, feitas nos meses de abril, maio, julho, agosto e setembro, em dois galpões climatizados da região oeste do Paraná, conforme demonstra a Tabela 1 .

Não foi encontrada Salmonella spp. nos pools de fragmentos de coração, fígado e baço e pool de ceco e tonsilas cecais, conforme demonstra a Tabela 2. 
Tabela 1. Resultados da pesquisa de Samonella spp. em galpões climatizados da região oeste do Paraná, PR, 2011.

\begin{tabular}{lcccc}
\hline Meses & \multicolumn{2}{c}{ Swab de cloaca } & \multicolumn{2}{c}{ Swab de arrasto } \\
\hline & Aviário 01 & Aviário 02 & Aviário 01 & Aviário 02 \\
\hline Abril & $0 / 100 *$ & $0 / 100 *$ & $0 / 2 * *$ & $0 / 2 * *$ \\
Maio & $0 / 100$ & $0 / 100$ & $0 / 2$ & $0 / 2$ \\
Julho & $0 / 100$ & $0 / 100$ & $0 / 2$ & $0 / 2$ \\
Agosto & $0 / 100$ & $0 / 100$ & $0 / 2$ & $0 / 2$ \\
outubro & $0 / 100$ & $0 / 100$ & $0 / 2$ & $0 / 2$ \\
\hline
\end{tabular}

* Número de amostras positivas para Salmonella spp. de Swab de cloaca, em relação ao número total de amostras testadas.

** Número de amostras positivas para Salmonella spp. de ceco e tonsilas fecais, em relação ao número total de amostras testadas. Fonte: Elaboração dos autores.

Tabela 2. Pesquisa de Salmonella spp. em órgãos obtidos de necropsia em aves provenientes de granjas climatizados da região oeste do Paraná, PR, 2011.

\begin{tabular}{lcccc}
\hline & \multicolumn{2}{c}{ Coração, fígado e baço } & \multicolumn{2}{c}{ Ceco e tonsilas cecais } \\
\hline Meses & Aviário 01 & Aviário 02 & Aviário 01 & Aviário 02 \\
\hline Julho & $0 / 10^{*}$ & $0 / 10^{*}$ & $0 / 10^{* *}$ & $0 / 10$ ** \\
Agosto & $0 / 10$ & $0 / 10$ & $0 / 10$ & $0 / 10$ \\
outubro & $0 / 10$ & $0 / 10$ & $0 / 10$ & $0 / 10$ \\
\hline
\end{tabular}

* Número de amostras positivas para Salmonella spp.de fragmentos do coração, fígado e baço, em relação ao número total de amostras testadas.

** Número de amostras positivas para Salmonella spp. de ceco e tonsilas fecais, em relação ao número total de amostras testadas.

Fonte: Elaboração dos autores.

\section{Discussão}

A pesquisa de Salmonella em galpões de frangos de corte é importante porque as aves infectadas com micro-organismos adaptados ao hospedeiro apresentam sinais clínicos graves, que é o caso das $S$. Pullorum e $S$. Gallinarum. Já a salmonellas paratíficas ocasionam uma queda na produção do plantel avícola, geralmente sem manifestar clinicamente a presença deste patógeno, entretanto pode ser transmitida para outras espécies animais através de excretas, aves infectadas ou através de seus produtos contaminados (PEREIRA; SILVA, 2005)

Dos dez lotes amostrados para pesquisa de Salmonella ssp. em swabs de cloaca, swab de arrasto e pool de fragmentos de órgãos foram negativos para este patógeno. Sugere-se que estes resultados sejam conseqüência do alto controle sanitário da empresa fornecedora dos pintinhos de corte para os dois galpões. Outro aspecto a ser destacado é que a empresa fornecedora mantém um monitoramento segundo o Plano Nacional de Sanidade Avícola (PNSA) em seus estabelecimentos de reprodutoras e aves comerciais, bem como programas de redução de patógenos na indústria, e programa de Análises de Perigos e Pontos Críticos de Controle (HACCP) em todo o complexo avícola, para controlar a propagação deste patógeno nos seus plantéis de aves e seus produtos.

Resultados semelhantes a este trabalho foram encontrados por Moreira (2002) ao examinar 300 pintinhos de corte pela técnica de $s w a b$ de cloaca em três empresas avícolas localizadas em Fortaleza (CE) com o objetivo de pesquisar a presença de Salmonella sp. Este autor obteve resultado negativo em todas as amostras, demonstrando que os pintinhos da Região Metropolitana de Fortaleza (CE) apresentam boa qualidade microbiológica quanto à presença de Salmonella. 
Martins (2009) também obteve resultados negativos quando rastreou Salmonella Enteritidis através do gene invA pela técnica de PCR em aves de corte e postura de ovos nas granjas comerciais do Estado do Espírito Santo. As 204 amostras de swab de cloaca apresentaram negatividade para Salmonella Enteritidis.

Koch (2006), analisou a prevalência de salmonelose em criações não tecnificadas de Gallus gallus de doze áreas no Distrito Federal, em 300 aves adultas, através de swab de cloaca e não detectou nenhum isolado de Salmonella nas amostras analisadas.

Já Seliter et al. (2007) pesquisaram Salmonella spp. em aves de corte de granjas avícolas da região sul do Rio Grande do Sul, 77 amostras por meio de swab cloacal, provenientes de 53 granjas avícolas, onde cada $s w a b$ amostrou duas aves, totalizando 154 frangos de corte. Das setenta e sete amostras avaliadas, em apenas duas (3\%), houve a presença de Salmonella spp.

Boni, Carrijo e Fascina (2011) pesquisaram a ocorrência de Salmonella spp. em aviários de frangos de corte e em produtos de abatedouro avícola na região central de Mato Grosso do Sul, analisando 134 swabs de arrasto em aviários de frangos de corte em cinco municípios diferentes. Verificaram que $11,28 \%$ das 257 amostras apresentaram resultados positivos para Salmonella (1,95\%). Concluiram que há ocorrência de diferentes sorovares de Salmonella spp. nos aviários da região central de Mato Grosso do Sul.

Andreatti Filho et al. (2009) pesquisaram Salmonella spp. em granjas de frangos de corte no estado de São Paulo por meio de swabs de arrasto. Das 806 amostras coletadas 22 foram positivas para Salmonella spp. Foram encontrados 11 sorotipos, quatro Salmonella enterica subespécie Enterica, duas Enteretidis, duas Infantis, uma Kentucky, uma Rissen e uma Senftenberg.

Perducini et al. (2011) pesquisaram Salmonella spp. em 129 pintos de corte de um dia comercializados em quatro agropecuárias de Santa Catarina. A partir de amostras de fígado e saco vitelínico em pool de três aves por amostras, foi isolada Salmonella Typhimurium de um pool de fígados (2,32\%). Este isolamento da Salmonella Tiphymurium em aves de um dia comercializadas para produção não industrial em Santa Catarina, pode ser um risco potencial de transmissão da mesma para os humanos e também para o sistema de produção industrial, uma vez que aves infectadas com este sorovar podem ser assintomáticas e mesmo assim serem transmissoras.

Camacho et al. (2008) pesquisaram a prevalência de Salmonella spp. em frangos, no Rio Grande do Sul, nos primeiros anos de implantação do Programa de Redução de Patógenos, do Ministério da Agricultura, da Pecuária e do Abastecimento (MAPA). Foram colhidos 131 swabs cloacais de aves de granjas avícolas de cinco municípios do sul do Rio grande do Sul no período de 20042008. Pode-se observar a redução da prevalência na população investigada, nos anos de 2004 a 2008, os quais apresentaram taxas de $8,33 \%, 2,44 \%, 2,38 \%$, $0 \%$ e $0 \%$, respectivamente. Os maiores resultados de isolamento foram observados nos anos de $2004 \mathrm{e}$ 2005, o que pode revelar dificuldade na implantação dos programas de controle de qualidade nos primeiros anos.

Esta grande diversidade de resultados apresentados nos trabalhos descritos, demonstra que as regiões que apresentaram maior positividade para Salmonella foram as regiões sul, centro oeste e sudeste do Brasil onde estão as maiores concentrações de aves criadas em confinamento, e apesar das indústrias de produtos de origem animal e os estabelecimentos avícolas de reprodutoras, como estabelecimentos avícolas comerciais e de aves de postura estarem controlando e monitorando sanitariamente os programas de redução e controle deste patógeno exigidos pelo MAPA, ainda assim, ocorre a introdução, multiplicação e disseminação da Salmonella spp, dificultando seu controle e tratamento. 
Nas regiões onde foram encontrados resultados com nenhuma ou baixa prevalência deste patógeno, pode ser devido ao fato destas regiões terem menor população de aves criadas em confinamento, isso diminui a entrada e disseminação da Salmonella spp, desde que empresas adotem medidas e procedimentos de cuidados com a saúde do plantel de aves em todas as etapas de criação, com interação com os diversos setores que compõem o sistema produtivo, diminuindo assim o risco de infecções, aumentando a higiene dos plantéis, minimizando a contaminação do ecossistema e preservando saúde do consumidor.

Apesar das normativas que estabelecem normas para indústrias de produtos de origem animal (circular $n^{\circ} 175$ de 16/05/2005 - DIPOA/ MAPA) e medidas de certificação sanitária dos estabelecimentos avícolas (Portaria No 297, de 15 de junho de 2010), não é possível controlar a disseminação de Salmonella, pois a entrada do patógeno pode ser através da ração, por exemplo. Uma das formas de controlar esta variável seria a implantação de sistemas de peletização da ração, a qual destrói praticamente todas as formas viáveis de Salmonella (BACK; BELTRÃO; LEÃO, 2006) e que já vem sendo feita por muitas empresas integradoras.

Dentre as instruções para os consumidores previstas pela ANVISA através da Resolução RDC no 13 (02/01/2001), pode-se citar instruções como manter o alimento refrigerado ou congelado, descongelar somente no refrigerador ou microondas, separar alimentos crus dos cozidos, lavar com água e sabão as superfícies de trabalho (incluindo tábuas de corte), utensílios e mãos depois de manipular o alimento cru e consumir o alimento somente após frito, assado ou completamente cozido.

Numerosas estratégias podem ser adotadas para obter resultados consistentes no controle e disseminação da Salmonella spp nos planteis avícolas.
As empresas precisam implementar programas de biosseguridade para o controle de salmonelose em seus plantéis avícolas tais como: aquisição de aves, matérias-primas e rações livres de Salmonella, proteção ambiental, higiene, desinfecção e vazio sanitário, descarte de lotes positivos, aplicação de flora bacteriana normal de aves adultas em pintinhos (exclusão competitiva); peletização da ração; utilização de aditivos na ração (ácidos orgânicos) e fazer controle de farinhas feitas a partir de resíduos animais, vacinação; monitoria das aves através de métodos de sorologia e isolamento microbiológico a partir das aves e do ambiente, controle e insetos e vetores (NASCIMENTO; SANTOS, 2005; BACK; BELTRÃO; LEÃO, 2006).

Medidas gerais devem ser tomadas de forma a atingir todos os sorovares de Salmonella e se preciso, ações mais específicas devem ser implementadas contra sorovares de maior significância econômica e/ou em saúde pública (BARROW, 2007).

Os resultados negativos para Salmonella spp. encontrado em frangos de corte criados em dois galpões localizados no oeste do Paraná pesquisados por meio de swabs de cloaca, swabs de arrasto e fragmentos de órgãos, provavelmente se relacionam ao bom programa sanitário desenvolvido pela empresa.

Esses resultados mostram também a preocupação das empresas que trabalham com avicultura em evitar o aparecimento deste patógeno em planteis avícolas e, de forma mais intensa, a preocupação em impedir a presença de Salmonella paratíficas nos rebanhos avícolas da região estudada, para evitar a participação das aves em casos de infecção alimentar em seres humanos.

\section{Conclusão}

De acordo com os resultados obtidos no isolamento bacteriano, os frangos de corte provenientes de dois galpões climatizados situados na região oeste do Paraná, encontram-se em boas 
condições sanitárias. Este resultado deve estar associado à ausência de Salmonella no ambiente onde estas aves foram criadas

\section{Agradecimentos}

Agradecemos a Universidade Paranaense pelo financiamento do projeto e ao Departamento DE Medicina Veterinária da Universidade Federal do Paraná - Campus Palotina pelo acompanhamento no desenvolvimento das análises microbiológicas.

\section{Referencias}

ANDREATTI FILHO, R. L.; LIMA, E.T.; MENCONI, A.; ROCHA, T. S.; MARIETTO-GONÇALVES, G. A. Pesquisa de Salmonella ssp. em swabs de arrasto provenientes de granjas avícolas. Veterinária e Zootecnia, Botucatu, v. 16, n. 1, p. 190-194, mar. 2009.

AGÊNCIANACIONALDE VIGILÂNCIA SANITÁRIA - ANVISA. Resolução RDC no 13 (02/01/2001). Aprova o Regulamento Técnico para instrução de uso, preparo e conservação na rotulagem de carne de aves e seus miúdos crus, resfriados ou congelados. Disponível em: $<\mathrm{http}: / /$ www.anvisa.gov.br.>. Acesso em: 17 out. 2011.

BACK, A.; BELTRÃO, N.; LEÃO, J. A. Monitoria e controle de salmonela: aspectos práticos. In: VII SIMPÓSIO BRASIL SUL DE AVICULTURA, 1., 2006, Chapecó. Anais... Chapecó: Associação dos Médicos Veterinários do Oeste de Santa Catarina, 2006. p. 95-103.

BARBETTA, P. A. Estatística aplicada às ciências sociais. 3. ed. Florianópolis: UFSC, 1999.

BARROW, P. A. Salmonella infections: immune and non-immune protection with vaccines. Avian Pathology, Cambs, v. 36, n. 1, p. 1-13, 2007.

BERCHIERI JUNIOR, Â. Salmoneloses aviárias. In: BERCHIERT JUNIOR, Â; MACARI, M. Doenças das aves. Campinas: FACTA, 2000. p. 185-196.

BONI, H. F. K.; CARRIJO, A. S.; FASCINA, V. B. Ocorrência Salmonella spp. em aviários e abatedouro frangos na região central de Mato grosso do sul. Revista Brasileira Saúde e Produção Animal, Salvador, v. 12, n. 1, p. 84-95, 2011.

CAMACHO, N. N.; PRATES, D. da F.; LIMA, A. S.; SILVA, W. P. Avaliação de Salmonella spp. em camas de aviário, em frangos, e em carcaças de frangos no sul do Rio Grande do Sul, após implementação do Programa de Redução de Patógenos. In: ConGRESSO DE INICIAÇÃO CIENTÍFICA, 17.; ENCONTRO DE PÓS GRADUAÇÃO, 10., 2008, Pelotas. Anais... Pelotas: FAEM/UFPEL, 2008. p. 1-5.

COX, N. A.; BERRANG, M. E.; CASON, J. A. Salmonella penetration of egg shells and proliferation in broiler hatching eggs - a review. Poultry Science, Honduras, v. 79, n. 1, p. 1571-1574, 2000.

FRANCO, B. D. G. M.; LANDGRAF, M. Microbiologia dos alimentos. São Paulo: Atheneu, 2005.

GOTTARDI, C. P. T.; SOUZA, C. A. S.; SCHMIDT, V. Surtos de toxinfecção alimentar no município de Porto Alegre/RS, no período de 1995 a 2002. Revista Higiene Alimentar, São Paulo, v. 20, n. 143, p. 50-55, 2006.

INSTITUTOPARANAENSEDEDESENVOLVIMENTO ECONÔMICO E SOCIAL - IPARDES. 2012. Disponível em: $<$ http://www.ipardes.gov.br/index.php?pg_ conteudo $=1 \&$ cod_conteudo $=25>$. Acesso em: 20 jun. 2012 .

KOCH, H. G. Análise de prevalência de salmonelose em criações não tecnificadas de Gallus gallus no distrito federal. 2006. Dissertação (Mestrado em Ciências Agrárias) - Universidade de Brasília, Brasília.

LE MINOR, L. Typing of Salmonella species. Eur J Clin Microbiol Infect Dis, New York, v. 7, n. 2, p. 214-218, 1988.

MINISTÉRIO DA AGRICULTURA, PECUÁRIA E DO ABASTECIMENTO - MAPA. Secretaria de Defesa Agropecuária Portaria Ministerial $n^{0}$ 193, 19 de setembro de 1994. Institui o Programa Nacional de Sanidade Avícola e cria o Comitê Consultivo do PNSA. Ministério da Agricultura, Pecuária e Abastecimento. Disponível em: <http://extranet. agricultura.gov.br/sislegisconsulta/consultarLegislacao. do operacao $=$ visualizar\&id $=2635>$. Acesso em: 20 set. 2011.

MARTINS, F. A. F. Rastreamento e detecção de Salmonella enteritidis através do gene invA, pela técnica de PCR em tempo real, na avicultura de corte e postura de ovos nas granjas comerciais do Estado do Espírito Santo. Vila Velha: Instituto de Pesquisa e Desenvolvimento, 2009.

MOREIRA, A. P. O. Pesquisa de Salmonella sp. em frangos de corte de um dia de idade da Região Metropolitana de Fortaleza-CE. 2002. Dissertação (Programa de Pós-Graduação em Ciências Veterinária) Universidade Estadual do Ceará, Ceará.

NADVORNY, A.; FIGUEIREDO, D. M. S.; SCHIMIDT, V. Ocorrência de Samonella sp. em surtos de doenças 
transmitidas por alimentos no Rio Grande do Sul em 2000. Acta Scientiae Veterinarie, Porto Alegre, v. 32, n. 1, p. 47-51, 2004.

NASCIMENTO, V. P.; SANTOS, L. R. Salmonella Enteritidis: Controle, implicações em saúde pública e na qualidade dos produtos de origem avícola. In: SIMPÓSIO BRASIL SUL DE AVICULTURA, 7., 2005, Chapecó. Anais... Chapecó: Associação dos Médicos Veterinários do Oeste de Santa Catarina, 2005. p. 46-57.

PELZER, K. D. Salmonellosis. Zoonosis Update, Washington, v. 195, n. 4, p. 456-463, 1989.

PERDUCINI, G.; ROCHA D. T.; MORAES C. R.; BORSOI, A.; SCHMIDT, V. Presença de Salmonella spp. em pintos de um dia comercializados para produção não industrial em Santa Catarina. Acta Scientiae Veterinarie, Porto Alegre, v. 39, n. 1, p. 950, 2011.

PEREIRA, M. S.; SILVA, P. L. Prevalência de anticorpos Salmonella pullorum e identificação bacteriológica de Salmonella sp em galinhas "caipiras" em Uberlândia (MG). Guia Avicultura Industrial, Porto Feliz, n. 6, p. 22-23, 2005.

SCHARR, H. Controles de Salmonela na União Européia. In: CONFERÊNCIA APINCO, 2003, Campinas. Anais... Campinas: Facta, 2003. p. 357-368.
SELITER, C. P.; LIMA, A. S.; BASSANI, M. T.; MENDONÇA, K. S.; FRANÇA, R.; SILVA, W. P. Aves portadoras de Salmonella spp. como fator de risco para contaminação da indústria e do produto final. In: CIC CONGRESSO DE INICIAÇÃO CIENTÍFICA, 16., 2007, Pelotas. Anais... Pelotas: Faculdade de Agronomia Eliseu Maciel, 2007. p. 1-3.

SHINOHARA, N. K. S.; BARROS, V. B. B.; JIMENEZ, S. M.C.; MACHADO, E. C. L.; DUTRA, R.A. F.; FILHO, J.L. Salmonella spp., importante agente patogênico veiculado em alimentos. Ciência Saúde Coletiva, Rio de Janeiro, v. 13, n. 5, set./out. 2008.

TÉO, C. R. P. A. Avaliação epidemiológica dos surtos de salmonelose ocorridos no Paraná entre janeiro de 1999 e junho de 2001. 2002. Dissertação (Mestrado em Ciência e Tecnologia de Alimentos) - Universidade Estadual de Londrina, Londrina.

TESSARI, E. N. C.; CARDOSO, A. L. S. P.; CASTRO, A. G. M.; ZANATTA, G. F.; KANASHIRO, A. M. I. Incidência de Salmonella spp. em pintos de corte recémnascidos. Arquivos Instituto Biológico, São Paulo, v. 70, n. 3, p. 279-281, jul./set. 2003.

UNIÃO BRASILEIRA DE AVICULTURA - UBA. O ovo vale ouro. Avicultura Industrial, Itu, v. 1153, n. 2, p. 22-29, 2007. Disponível em: <http://www.uba.org.br>. Acesso em: 20 set 2011. 